\title{
Annular pancreas: a clinical, endoscopic, and immunohistochemical study
}

\author{
J F DOWSETT, J RODE, AND R C G RUSSELL \\ From the Departments of Gastroenterology, Pathology, and Surgery, The University College and Middlesex \\ Medical School, London
}

\begin{abstract}
SUMMARY A patient with annular pancreas presenting with severe upper abdominal pain is discussed. Endoscopic retrograde cholangiopancreatography (ERCP) was diagnostic, with successful injection of major and minor papillae showing pancreas divisum, an annular duct emptying at the major papilla and changes of severe chronic pancreatitis in all duct systems. Pylorus preserving pancreatoduodenectomy gave complete pain relief. The annulus was shown immunohistochemically to be entirely of ventral gland origin. Chronic pancreatitis was histologically less severe in the dorsal gland. Antegrade dye injection with $x$-ray showed dorsal to ventral connection in the resected specimen.
\end{abstract}

Endoscopic retrograde cholangiopancreatography has produced a better appreciation of abnormalities and anomalies of the pancreatobiliary duct systems and many more examples are now being documented during adult life. These include pancreas divisum with non-fusion of the dorsal and ventral pancreatic duct systems which occurs in 4-6\% of the population,' choledochal cysts, ${ }^{23}$ congenital short pancreas, ${ }^{45}$ abnormally long common channel, ${ }^{6}$ and annular pancreas. ${ }^{7-9}$ These findings may carry considerable clinical significance: pancreas divisum may be related to chronic pancreatitis if a relative stenosis of the accessory papilla occurs, choledochal cysts are premalignant and may lead to secondary biliary cirrhosis if unrecognised, congenital short pancreas may be mistaken for neoplastic obstruction of the pancreatic duct, long common channels may predispose to gall bladder carcinoma and annular pancreas may be the origin of numerous symptoms.

A sound understanding of basic pancreatoduodenal embryology and ERCP appearances is required $^{4-11}$ because of the routine use of ERCP for

Address for correspondence: Dr J F Dowsett, Department of Gastroenterology. The Middlesex Hospital, Mortimer Street, London W1N 8AA. Reccived for publication 15 July 1988 . diagnostic and preoperative assessment of pancreatic pain. ${ }^{12}$

\section{Case report}

A 23 year old Caucasian male presented in September 1987 with a history of recurrent attacks of epigastric and right upper quadrant pain since the age of 10 . Initially the attacks lasted two or three days, were of moderate severity, occurred one to three times annually and were exacerbated by eating and relieved by fasting. There was no anorexia, vomiting, nor weight loss. At the age of 16 , two severe attacks occurred lasting seven and 10 days and a barium meal was done which showed a 'non-specific' abnormality in the second part of the duodenum for which no further investigation was recommended. The pattern then returned to that suffered previously until the age of 21 (1985) when four severe attacks each lasting 10 days occurred. Three further severe attacks in 1986 were associated with lumbar backpain which remained for two weeks after resolution of other symptoms. There had been two severe attacks before presentation in 1987 and serum amylase was measured for the first time and was raised (1200 U/l). He was passing two stools daily which had clinical 
features of steatorrhoea. There was no family history of pancreatitis, gall stones nor hyperlipidaemia and no personal history of medical disorder except nocturnal epilepsy for which phenytoin had been prescribed. The patient had begun consuming alcohol at the age of 17 , averaging about $100 \mathrm{~g}$ per week, but had ceased ingestion six months before admission.

Physical examination, routine biochemistry and serum amylase were normal. Plain abdominal films revealed speckled calcification in the pancreatic head region and a separate lateral calcified oval opacity. Ultrasound suggested chronic pancreatitis of the pancreatic head with calcification and an abnormal parenchymal echo pattern but the body and tail appeared normal and no pseudocyst was evident. Computed tomography (CT) scanning suggested some non-specific periduodenal thickening and con-

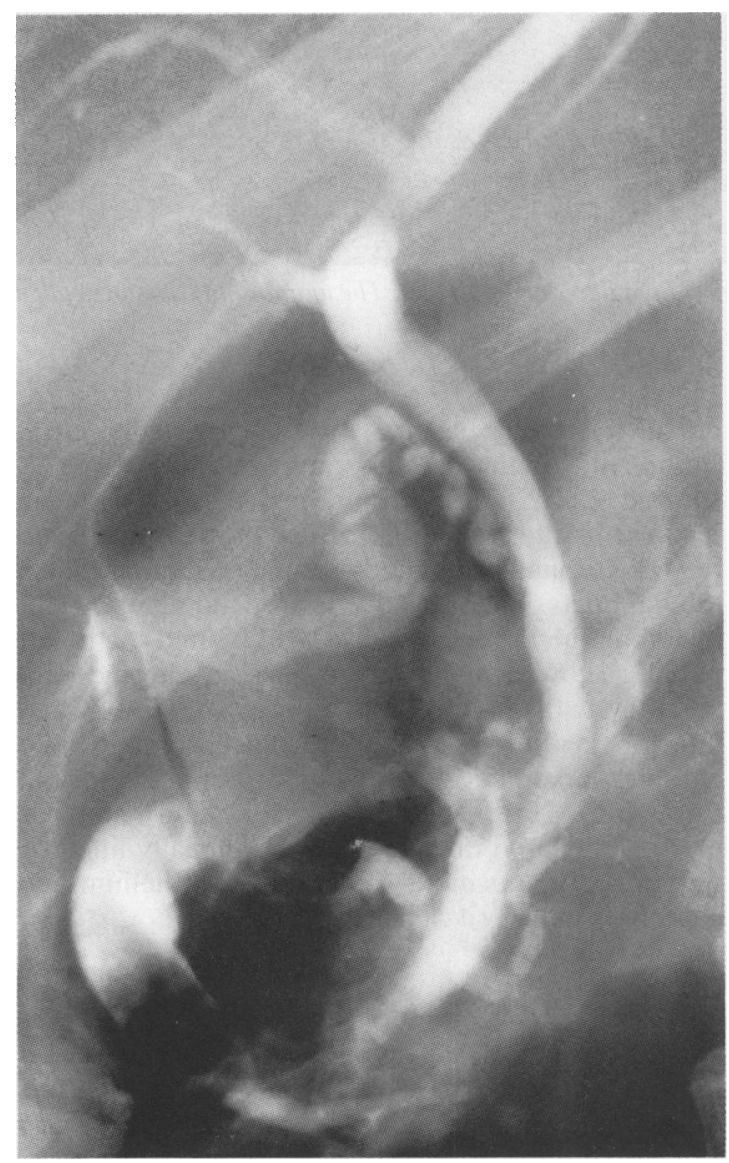

Fig. 1 Film of result of two separate injections at major papilla during ERCP. firmed intrapancreatic calcification. Side viewing duodenoscopy revealed moderate concentric narrowing of the second part of the duodenum just proximal to the papilla. The major and minor papillae were macroscopically normal. Cannulation of the major papilla showed a dilated, irregular annular pancreatic duct containing a stone and sludge and a normal biliary tree and gall bladder (Fig. 1). The dorsal pancreatic duct did not fill. Cannulation of the minor papilla using a fine tipped cannula (without secretin) revealed a dilated, irregular dorsal duct (Fig. 2). These ERCP findings suggested an annular pancreas with pancreas divisum and changes of severe chronic pancreatitis in all duct systems. Faecal fat excretion was raised at $13 \mathrm{~g} /$ day.

Because of the history of severe recurrent pain interfering with lifestyle and the ERCP findings suggestive of severe chronic pancreatitis of the entire gland but particularly the head, pylorus preserving pancreatoduodenectomy was advised. This was carried out without complication or the development of overt diabetes or further clinical pancreatic exocrine insufficiency. The patient was discharged free from pain 12 days postoperatively, taking oral pancreatic supplementation and has remained so nine months after surgery.

\section{PATHOLOGY}

The operation specimen comprised the head and neck of the pancreas measuring $6.5 \times 5 \times 4 \mathrm{~cm}$ with a $2 \mathrm{~cm}$ thick annular portion of the gland completely encircling the duodenum and a $19 \mathrm{~cm}$ C-loop of duodenum. After photographic documentation of the fresh specimen, it was injected with a radioopaque yellow resinous dye (Microfil-TM) from the slightly dilated $0.3 \mathrm{~cm}$ wide cut end of the dorsal duct. A probe was inserted into the duodenum through the common bile duct from its cut end for orientation purposes and the specimen was radiographed (Fig. 3a). The dye was seen to fill a slightly dilated dorsal duct system and drain through the accessory papilla. This included the ducts of the uncinate process. Also filled was the markedly dilated annular duct system which encircled the duodenum and drained via the major papilla from a different ostium than the common bile duct. The communication between annular/ventral and dorsal duct systems suggested that true divisum was not present. It is possible that injection at this pressure may show communication in many patients in whom the relatively low pressure injection at ERCP has suggested divisum.

After routine formalin fixation the entire pancreatic specimen was sliced horizontally into sections approximately $0.4 \mathrm{~cm}$ thick before paraffin processing and orientated embedding of the whole sections. A $1.8 \times 1.0 \mathrm{~cm}$ cylindrical stone was found impacted 


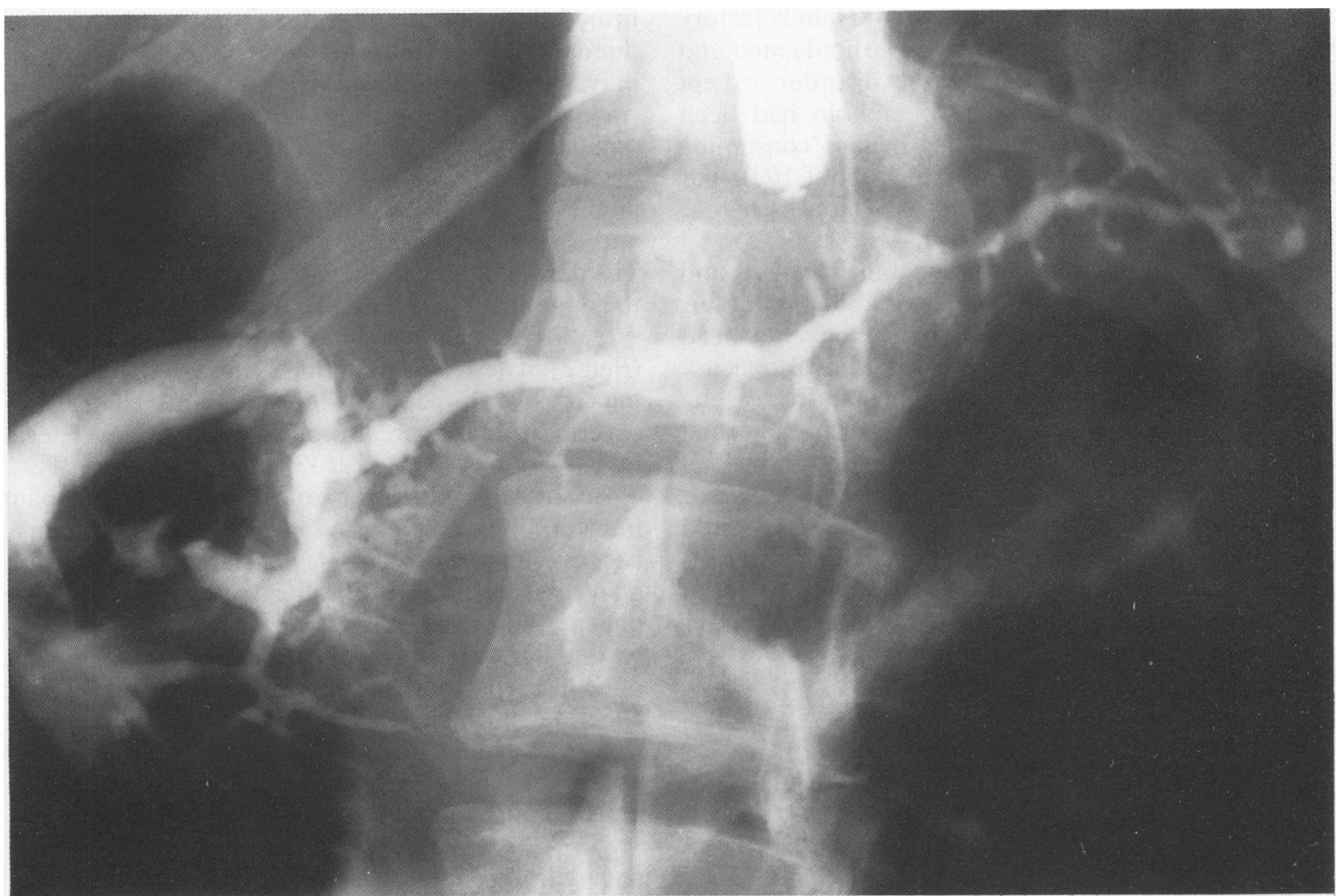

Fig. 2 Film of result of single injection at minor papilla (after major papilla) during ERCP. The annulus has remained filled from the previous major papilla injection but the biliary tree has emptied.

within the annular duct on the right lateral duodenal side. A round $0.3 \mathrm{~cm}$ stone was found occluding the ventral duct at its ostium in the major papilla. Smaller calcifications were found within side ducts throughout the annulus. The major portion of the pancreatic parenchyma within the head and neck appeared grossly normal, whilst there appeared to be an increase in connective tissue within the annulus (Fig. 3b).

Approximately 20 consecutive $5 \mu \mathrm{m}$ sections were cut from each tissue block and stained routinely with haematoxylin and eosin and immunohistochemically for neural and neuroendocrine markers (neurone specific enolase; protein gene product 9.5 ) and for pancreatic hormones (insulin; glucagon; somatostatin; pancreatic polypeptide). Applying previously established criteria for the differentiation of the two embryological derivatives in the adult pancreas, ${ }^{13.14}$ it could be clearly delineated that the entire annulus was of ventral gland origin, whilst the major part of the head, the neck and the uncinate process were of dorsal origin (Fig. 3c).

Pancreatitis of different severity was seen involving the two embryonic parts of the pancreas. The dorsally derived pancreas, as suggested by ultrasound and computed tomography but not by ERCP, showed only mild chronic pancreatitis with an increase in interlobular fibrous connective tissue and only occasional inspissated proteinaceous material in lobular ducts. The ventrally derived annular portion, including the lower posterior head behind the major papilla, showed moderate to marked chronic pancreatitis with loss of exocrine tissue, intra and interlobular fibrosis and periductal fibrosis. A mild chronic inflammatory cell infiltrate was present throughout the annular/ventral gland and its markedly dilated ductal system was focally lined by squamous or mucinous metaplastic epithelium and contained impacted calcifications.

\section{Discussion}

Annular pancreas was first described by Tiedman in $1818^{15}$ and named by Ecker in $1862 .^{16}$ Its incidence is unclear but has been calculated at about 1:20000. ${ }^{17}$ Its presentation tends to be bimodal with peaks neonatally and in the fourth to fifth decades. Surprisingly, equal numbers have been reported in adults 


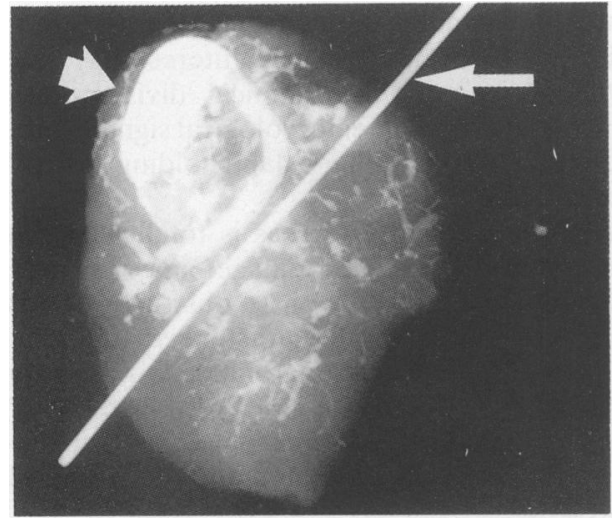

(a)
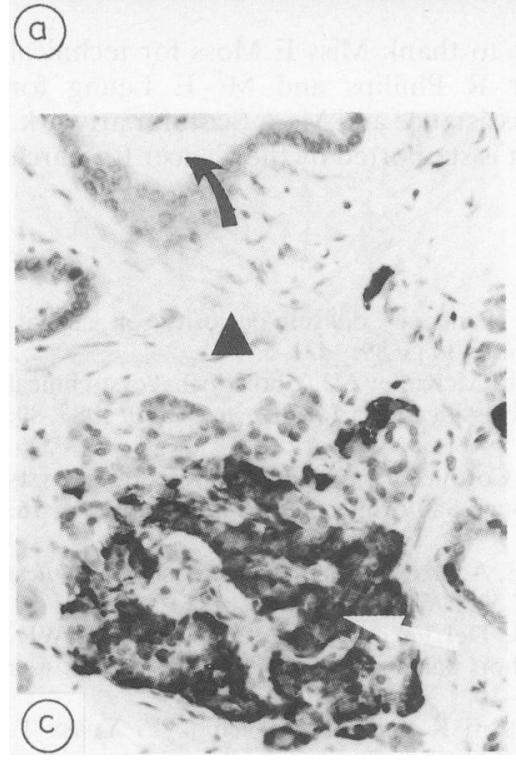

and children. "Neonatal presentation is usually with congenital duodenal obstruction, wherein it contributes $15 \%$ of all cases. ${ }^{17}$ The pregnancy may have been associated with polyhydramnios. ${ }^{19}$ The obstruction is generally classified as intrinsic as pancreatic tissue is often intimately related to the wall of the duodenum. ${ }^{17}$ Other congenital abnormalities are often associated. ${ }^{19}$ Treatment is by surgical bypass. Adult presentation may be with duodenal stenosis, peptic ulceration, chronic pancreatitis or as an incidental finding. ${ }^{10}$ The most common adult symptom is upper abdominal pain. The coincident peptic ulcer disease which has been reported in 29$48 \%$ of adult cases, ${ }^{72 n}$ may be related to gastric stasis and antral over distension with secondary hypergastrinaemia ${ }^{21}$ and the chronic pancreatitis which has been found in $14-50 \%$ of adult cases ${ }^{7222}$ to poor duct drainage from relative outlet obstruction ${ }^{22.3}$ as well as a possible intrinsic hypersusceptibility of the annular gland to damage. Unless another factor is present the chronic pancreatitis has always appeared limited to the annulus itself." Biliary obstruction is now believed a rare complication ${ }^{21}$ despite early reports to the contrary. ${ }^{1 x}$ Most cases have been diagnosed by the classical changes seen with hypotonic duodenography ${ }^{24}$ but recently CT scanning has also proved useful if careful attention is given to oral contrast ingestion and patient positioning. ${ }^{2+26}$

The aetiopathogenesis of annular pancreas is unknown. It may be a component of a more generalised disorder of embryogenesis when associated with trisomy 21 , tracheo-oesophageal fistula or cardiorenal abnormalities or may occur alone or with local duodenal abnormality only. ${ }^{17}$ Neonatal cases are 
associated with other congenital abnormalities in about $80 \%$ of cases and adult cases in about $20 \%$. Three main theories have been espoused with supporting evidence. Lecco in $1910^{27}$ suggested that the ventral pancreas adhered to surrounding tissues at its site of origin in the ventral mesogastrium and therefore maintained an anatomically true ventral connection throughout its $270^{\circ}$ migration to the adult position. Baldwin in $1910^{28}$ suggested that there was a failure of atrophy of the left component of the ventral pancreatic anlage which, as in Lecco's theory, maintains a true ventral connection. The occasional demonstration of separate duodenal openings of the annular and ventral pancreases ${ }^{29}$ and of drainage of the annular pancreas into santorinis duct of the dorsal pancreas, ${ }^{8}$ favours the latter theory with two separate ventral duct systems. The final theory, expressed by Verga in 1972," suggests that the primary abnormality is duodenal with the pancreas 'filling the space' around a narrowed duodenum. This is supported by the fact that many annular pancreases are partially intramural. ${ }^{18}$ It must also be noted that the annulus may be fibromuscular rather than true pancreatic tissue. ${ }^{30}$

This case of annular pancreas with ERCP divisum and ERCP and histological chronic pancreatitis affecting the dorsal, ventral, and annular components is important for several reasons. First, it further illustrates the important role of ERCP in the assessment of patients with presumed idiopathic pancreatitis wherein therapeutically important information is obtained relatively non-invasively. ${ }^{12}$ The finding of annular pancreas is obviously rare, but focal strictures and periampullary disorders are found more commonly. Second, this is one of only a few cases of successful accessory papilla injection in patients with this anomaly.$^{18}$ The incidence of ERCP divisum in cases of annular pancreas has been estimated as around $36 \% .{ }^{22}$ In this case, antegrade resin injection showed a dorsal to ventral connection and it is possible that many cases of ERCP diagnosed divisum do indeed have a true anatomical (though not physiological) connection, but that an increased injection pressure is needed to show it. This pressure if applied during retrograde pancreatography would cause unwanted acinar filling of the ventral gland. Third, chronic pancreatitis was documented in all duct systems, although more severe in the annular gland. It is likely that obstruction was aetiologically involved as the annular gland opened aberrantly at the major papilla and the dorsal gland was draining predominantly through the accessory papilla which is known to impede outflow in some patients. Finally, immunohistochemistry has confirmed for the first time that an entire annulus is of ventral origin. This was originally suggested by Sessa ${ }^{13}$ and proves that the final $90^{\circ}$ of annular duodenal circumscription is derived from the ventral gland. Interestingly, the ventral/dorsal immunohistochemical division may have functional as well as embryological significance, with the ventral periampullary gland holding more of a regulatory role. ${ }^{13} 14$

In summary, annular pancreas is totally derived from the ventral pancreatic anlage, may produce chronic pancreatitis possibly on an obstructive basis in adults and may be well characterised by endoscopic retrograde pancreatography, which may require accessory duct cannulation. Although ERCP may suggest pancreas divisum, anatomical connection may be evident on antegrade pathological studies.

We would like to thank Miss E Moss for technical assistance, $\mathrm{Mr} \mathrm{R}$ Phillips and $\mathrm{Mr} \mathrm{E}$ Leung for photographic assistance and Ms A Scott for artwork. Dr J F Dowsett is supported by the Cancer Research Campaign.

\section{References}

1 Cotton PB. Pancreas divisum-curiosity or culprit. Gastroenterology 1985; 89: 1431-5.

2 Crittenden SL, McKinley MJ. Choledochal cyst-clinical features and classification. Am J Gastroenterol 1985; 80: 643-7.

3 Leung JW, Cotton PB. Congenital bile duct Cysts draining through Santorini's duct. Endoscopy 1984; 16: 167-8.

4 Rosenstock E, Achkar E. A short pancreas. Gastrointest Endosc 1986; 32: 296-7.

5 Gilinsky NH, Del Favoro G, Cotton PB, Lees WR. Congenital short pancreas - a report of two cases. Gut 1985; 26: 304-10.

6 Kato O, Hattori K, Suzuki T, Tachino F, Yuasa T. Clinical significance of anomalous pancreatobiliary union. Gastrointest Endosc 1983; 29: 94-8.

7 Dharmsathaphorn K, Burrell M, Dobbins J. Diagnosis of annular pancreas with endoscopic retrograde cholangiopancreatography. Gastroenterology 1979; 77: 1109-14.

8 Clifford KMA. Annular pancreas diagnosed by endoscopic retrograde choledocho-pancreatography (ERCP). Br J Radiol 1980; 53: 593-5.

9 Glazer GM, Margulis AR. Annular pancreas - etiology and diagnosis using endoscopic retrograde cholangiopancreatography. Radiology 1979; 133: 303-6.

10 Kiernan PD, ReMine SG, Kiernan PC, ReMine WH. Annular pancreas - Mayo Clinic experience from 1957 to 1976 with a review of the literature. Arch Surg 1980; 115: 46-50.

11 Pantoja E, Nagy F, Thomas HA, Zambernard J, Bartley MC. Annular pancreas. Med Radiogr Photogr 1985; 61: 2-9.

12 Feller ER. Endoscopic retrograde cholangiopancreatography in the diagnosis of unexplained pancreatitis. Arch Intern Med 1984; 144: 1797-9. 
13 Sessa F, Fiocca R, Tenti P, Solcia E, Tavani E, Pliteri S. Pancreatic polypeptide rich tissue in the annular pancreas - a distinctive feature of ventral primordium derivatives. Virchows Arch [Pathol Anat] 1983; 399: 227-32.

14 Dhillon AP, Rode J, Lowes JR, Moss E, Cotton PB. Morphological distinction of ventral and dorsal anlagen in adult pancreas [Abstract]. J Pathol 1986; 146: 263$4 \mathrm{~A}$.

15 Tiedmann F. Uber die verschiedenheiten des ausfuhrangsganges der bauchspeicheldruse bei den menschen und saugetieren. Dtsch Arch Physiol 1818; 4: 403.

16 Ecker A. Bildungsfehler des pankreas und des herzens. Z Art Med 1862; 14: 354.

17 Salonen IS. Congenital duodenal obstruction - a review of the literature and a clinical study of 66 patients, including a histopathological study of annular pancreas and a follow up of 36 survivors. Acta Paediatr Scand (suppl) 1978; 272: 1-87.

18 Lehman GA, O'connor KW. Coexistence of annular pancreas and pancreas divisum-ERCP diagnosis. Gastrointest Endosc 1985; 31: 25-8.

19 Merrill JR, Raffensperger JG. Paediatric annular pancreas - twenty years experience. J Pediatr Surg 1976; 11: $921-5$.

20 Thomford NR, Knight PR, Pace WC. Annular pancreas in the adult-selection of operation. Ann Surg 1972; 176: $159-62$.
21 Johnston DWB. Annular pancreas - a new classification and clinical observations. Can J Surg 1978; 21: 241-4.

22 Gilinsky NH, Lewis JW, Fleuck JA, Fried AM. Annular pancreas associated with diffuse chronic pancreatitis. Am J Gastroenterol 1987; 82: 681-4.

23 Chevillotte G, Sahel J, Raiilat A, Sarles H. Annular pancreas - report of one case associated with acute pancreatitis and diagnosed by endoscopic retrograde pancreatography. Dig Dis Sci 1984; 29: 75-7.

24 Bernard C, Regent D, Delgoffe C, et al. Apport de la radiologie au diagnostic des formes compliques de pancreas annulare chez l'adulte. J Radiol 1984; 65: 83943.

25 Novetsky GJ, Berlin L, Smith C, Epstein AJ. CT diagnosis of annular pancreas. J Comput Assist Tomogr 1984; 8: 1031-2.

26 Ahmed A, Chan KF, Sook Song I. Annular Pancreas. J Comput Assist Tomogr 1982; 6: 409-11.

27 Lecco TM. Zur Morphologie des pankreas annulare. Sitzungb Akad Wissensch 1910; 119: 391-406.

28 Baldwin WM. A specimen of annular pancreas. Anat Sec 1910; 4: 299-304.

29 Whelan IJ, Hamilton GB. Annular pancreas. Ann Surg 1957; 146: 252-62.

30 Steinberg A, Zelikovski A, Abu-Dalu J, Urca I. Fibromuscular annular pancreas - a variant of pancreatic malformation? Int Surg 1978; 63: 170-2. 